Cabrera Balbuena, Iria.

Profesora de animación. Escuela Superior Politécnica del Litoral. Escuela de Diseño y Comunicación Visual. Guayaquil. Ecuador.

\title{
Proto stop-motion: Análisis de las primeras apariciones del stop motion en el cine de acción real
}

\section{Proto stop-motion: Analysis of first stop motion appearances in live action}

TIPO DE TRABAJO: Comunicación.

\author{
PALABRAS CLAVE
}

Stop motion, proto-stop motion, cine de trucaje, Méliès, magia, efectos especiales.

KEY WORDS

Stop motion, proto-stop motion, trick films, Méliès, magic, special effects.

RESUMEN

A lo largo de la historia, plasmar el movimiento ha sido una inquietud para el ser humano. Previo a las primeras películas, encontramos muestras como pinturas en cuevas o juguetes ópticos que se engloban dentro de los términos pre-cine o proto-cine. De igual manera, si nos referimos a la animación, manejamos la categoría de proto animación. El stop motion es una técnica animada en la que realizamos sustituciones de objetos o personajes para generar la ilusión de movimiento, en medio de la acción de parar y reiniciar nuestra cámara repetidamente. Las primeras apariciones de esta técnica tienen lugar en el cine de acción real y son conocidas como trucos de sustitución. En este trabajo se revisan, analizan y clasifican considerando la técnica, proponiendo la categoría de proto-stop motion como contenedora de los antecedentes de la animación stop motion contemporánea.

\section{ABSTRACT}

Throughout history, shaping the movement has been a concern for human beings. Samples of that fact have been found prior to the first films, such as cave paintings or optical toys, both included within the terms "pre-cinema" or "proto-cinema". Similarly, if we refer to animation, we use the category of proto animation. Stop motion is an animated technique in which we substitute objects and characters to generate the illusion of movement in the middle of the action of stopping and restarting our camera repeatedly. The first appearances of this type of animation take place in real action cinema and are known as substitution tricks. They are reviewed, analyzed and classified in this research work, considering the technique and proposing the category of proto-stop motion as a container of the antecedents of contemporary stop motion animation.

\section{INTRODUCCIÓN}

El contexto político, social y los avances tecnológicos son relevantes en la creación del cine y por lo tanto, de la animación stop motion. El nacimiento de esta técnica está muy ligada al cine de acción real y su aparición tiene lugar en la Segunda Revolución Industrial. Observamos que en ciertas películas de acción real hay segmentos que sentarán las bases de la animación stop motion tal y como la conocemos actualmente. Estas primeras muestras de trucaje en el cine, que observamos se dan en su gran mayoría en películas con temática mágica, intuimos que se tratan del stop motion más primitivo. 


\section{METODOLOGÍA}

Como metodología a seguir en el presente trabajo se ha partido del método cualitativo, desde la observación y el análisis de obras. Dentro de esta metodología podemos seguir ciertos aspectos para llevarla a cabo, sin tener que utilizarlos todos. En concreto, para el tema tratado, se parte de la observación participante que nos propone Martínez Barragán como parte del método cualitativo en las Bellas Artes:

Como participantes nos dirigimos a la confrontación de las obras, a su análisis. Nuestra mirada no es la del historiador que ante la obra busca datos contextuales, cronologías, correlación de autores, etc. Tampoco vemos en primer lugar, la adecuación de la obra a una teoría estética o a un desarrollo filosófico. Tampoco vemos la coherencia expositiva de las obras dentro de un recinto o museo. (...) después de sentir empatía con la obra, nos acercamos para ver cómo se ha hecho, que procesos están presentes en ella, con qué se ha construido (...) (Barragán, 2011: 56)

Partiendo de este método, analizamos cómo se han hecho los trucos de sustitución en estas primeras películas, que reclasificamos según temática para proponer un nuevo punto de vista y comprensión del origen del stop motion como un elemento que aunque forma parte del cine, podemos situarlo de manera independiente en la historia propia de la animación.

\section{DESARROLLO}

A continuación hacemos un acercamiento a la técnica de animación stop motion, en relación al término y concepto. Posteriormente se propone el término proto-stop motion entendido como categoría inclusiva de las primeras sustituciones en el cine de acción real a modo de antecedentes de la técnica específica denominada animación stop motion. Para comprender esta nueva definición, nos apoyamos en los términos de proto-cine y proto-animación. Para reclasificar los tipos de muestras proto-stop motion, se realiza el análisis, según la temática tratada, de algunas de las primeras películas de acción real, reconociendo dos tipos diferenciados: El cine mágico y el de trucaje. Esta clasificación se utiliza para exponer dichas muestras como el stop motion más primitivo que dará lugar al stop motion animado contemporáneo.

\section{La animación stop motion. Definición}

La animación stop motion es una técnica animada en la que inicialmente, se paraba la cámara de cine y se reiniciaba mientras se creaban sustituciones en el plano utilizando objetos, marionetas diseñadas para este fin o incluso actores, siendo en este último caso conocida como pixilación. Este término, atribuido a Gran Munro, se refiere a una técnica no tradicional de stop motion, en la que normalmente se anima una persona como si fuese un muñeco (Tom Gassek, 2017:3).

La técnica del stop motion surge como "ayuda" al cine de acción real y evoluciona hasta convertirse en una técnica de animación, independiente del cine. Actualmente para realizar películas de stop motion no se utilizan cámaras de cine sino que valiéndose de cámaras de fotografía digital se toman imágenes independientes que posteriormente son editadas para generar la ilusión de movimiento. Siguiendo la evolución de esta técnica, observamos que el stop motion no solamente es un término que define una técnica, sino que engloba un proceso, que guarda una estrecha relación con el cine de acción real. Las fases de creación de una película stop motion actualmente se corresponden con las del cine: preproducción, producción y postproducción. Como términos para definir este tipo de animación partimos de la lengua inglesa, en la que se origina la palabra stop motion. Donald Crafton, Toni Dalton o Harryhausen manejan diferentes términos para referirse a las muestras previas de este tipo de animación: stopping motion, stop action, stop trick, trick of sustitution, o stopped camera substitution antes de utilizar stop motion, término referido solamente a las películas realizadas fotograma a fotograma, enteramente con esta técnica. Estas palabras en inglés las traducimos como "parando el movimiento", "parando la acción", "truco de sustitución" o "sustitución de la cámara parada". Sin embargo, ya encontramos el término stop motion unido al de "sustitución" en Charles Musser para definir el truco de la decapitación de la reina María, del que hablaremos más adelante. Al leer textos en español, la técnica previa a la animación stop motion se define como "paso de manivela" y hace referencia a la acción que se realizaba con las cámaras de cine para dar lugar a sustituciones en la pantalla. Todos estos términos hacen alusión a lo mismo: parar el movimiento, parar la acción y parar la cámara de filmación para realizar una sustitución. Abarca una amplia gama de prácticas que implican la captura del movimiento frame-by-frame (fotograma a fotograma) de un objeto corpóreo que se reutiliza una y otra vez (Furniss, 2017: 184).

A pesar de que el primer truco de sustitución en el cine se registra en el año 1895, el descubrimiento de la técnica del stop motion se le atribuye al ilusionista francés Georges Méliès. Un día de rodaje en la Place de L'Opéra del año 1.896, su cámara se atasca durante apenas un minuto, tiempo que tarda en desbloquearla. Posteriormente, al proyectar la película observa que un autobús se ha transformado en un coche fúnebre. Así es como descubre el paso de manivela o stopping motion del que se valdrá para realizar trucos de sustitución en sus películas parando la filmación, realizando sustituciones previamente planeadas y volviendo a activar la cámara. 
Sin embargo, en este momento aún no se hace uso del stop motion como una técnica de animación en la que se sustituyen a los actores por muñecos y se desarrolla el filme enteramente con decorados realizados en miniatura. Es una herramienta, apoyo al cine, mediante la que se generan efectos especiales y trucos de magia. "El reemplazo por stop motion, aunque es un truco ingenioso y efectivo, no implica, por supuesto, la animación."(Tony Dalton y Harryhausen, 2008:38).

\section{El proto-stop motion. Cine mágico y de trucaje}

Para referirnos a las muestras previas al cine de acción real, utilizamos los términos pre-cine y protocine y en ellas englobamos los trabajos más primitivos que contribuyeron a su desarrollo. "El protocine, praxis fílmica inscrita en un período cronológico que admite la referencia a prácticas pre-cinematográficas y espectáculos afines, (...)” (Cuéllar, 1999:177-178). Todos estos dibujos, espectáculos, recortables, pinturas o relieves, así como los juguetes ópticos están contenidos dentro del término protocine, ya que son muestras de lo que sería en un futuro el cine. De la mano del protocine y para englobar los inicios de la animación, nos encontramos con la definición de proto animación como "empleo de técnicas utilizadas más tarde por animadores y que no están estrictamente o enteramente realizadas fotograma a fotograma" (Nelmes, 1.996: 215). Un buen ejemplo es la película Humorous Phaces of Funny Faces (Blackton, 1906) realizada con tiza sobre pizarra que se vale del truco de sustitución para mostrarnos, a modo de adelanto, cómo serían los futuros dibujos animados. Se trata de un ejercicio previo al futuro cine de animación pero sin serlo en su totalidad, razón por la que se sitúa como un trabajo de proto animación.

Partiendo de estos dos conceptos, proponemos como categoría específica dentro de la proto animación, el término proto-stop motion para englobar las primeras muestras contenidas en el cine de imagen real como los antecedentes de una técnica de animación en particular: La animación stop motion. Clasificamos la categoría de proto-stop motion en cine de trucaje y cine mágico. Realizamos esta diferenciación respecto a la temática tratada en las películas en las que hace su aparición, desde 1.895 hasta aproximadamente 1.900 cuando damos por concluido el cine mágico.

Es importante destacar que durante los inicios del cine y por tanto, de la animación, el contexto tiene mucho peso en las producciones que se realizan: los temas tratados están muy relacionados con las preocupaciones de las personas de la época. Y esto, junto al descubrimiento del paso de manivela y su posterior desarrollo tiene mucho que ver en la aparición de algunas películas. Se trata de algo circular: Un avance tecnológico ayuda a dar forma a historias ficticias y estas historias pueden materializarse en el cine gracias al conocimiento para su ejecución técnica.

El cine siempre ha estado relacionado con la magia. En el S.XIX los espectáculos de magia gozan de gran popularidad y ciertos sectores de la población pueden acudir, gracias al tiempo libre que poseen debido a los avances en las ciudades industriales. El atributo mágico del cine ya proviene del invento del primer proyector en el S.XVI. Su inventor, Athanasius Kirchner denominó a su artefacto como mágico. Y este atributo de la linterna mágica lo heredará el cine hasta el punto de que un empleado de Lumière será tomado por brujo al realizar la proyección de un zar (Gubern, 2014:15).

Si la animación stop motion hace sus primeras apariciones como parte del cine de acción real, entonces este atributo mágico también se puede vincular a la técnica animada. El animador, encargado, a través de su mano, de conseguir la ilusión de movimiento, toma una fotografía, cambia elementos o mueve las marionetas para volver a fotografiar. Es importante tener en cuenta el papel de la magia en la sociedad de finales del S.XIX como telón de fondo para su aparición en el cine y por tanto, como parte de la animación stop motion más primitiva. Entendemos que dentro de la historia de la animación stop motion existen dos etapas diferenciadas que marcan un antes y un después. La primera de ellas tiene que ver con un stop motion más primitivo aplicado como recurso técnico (sin pretensión de ser animación) como en Fun in a Bakery shop (Edison Company, 1902), donde se utiliza el truco de sustitución o paso de manivela en un segmento concreto sin que la película esté realizada enteramente fotograma a fotograma. La siguiente etapa, como podemos observar en El teatro eléctrico de Bob (Chomón, 1909) casi la totalidad del filme está rodada fotograma a fotograma, al igual que en el stop motion actual. En este momento, el truco de sustitución pasa a convertirse en un recurso artístico sobre el que generar una idea para transmitir al espectador.

Nos valemos del término proto-stop motion (como ramificación proveniente de la proto animación) para clasificar este tipo de películas que tratan de reproducir trucos de magia o efectos especiales como el germen previo a partir del cual comienzan a realizarse segmentos animados antes de la creación de películas totalmente realizadas en stop motion. 
El cine de trucaje lo podemos localizar a finales del S.XIX, posteriormente a las películas de los Lumiére, de corte netamente documental. A pesar de que el descubrimiento técnico del paso de manivela, como hemos visto anteriormente, se le atribuye a Georges Méliès, la técnica ya se había utilizado previamente en 1.895 pero no es hasta que lo experimenta Méliès que se convierte en un recurso utilizado por muchos interesados en la imagen o provenientes del mundo de la pintura y la fotografía, que comienzan a plantearse que este invento no tiene por qué ser meramente técnico. Se realizan pequeñas películas de ficción o integrando lo que actualmente conocemos como efectos especiales. El truco de sustitución pionero en la historia del cine lo encontramos en la película Mary Queen of Scots (Alfred Clarke, 1.895) considerada como la contenedora de la primera secuencia de efectos especiales en el cine. Esta película, de unos segundos de duración, trata la ejecución de María Estuardo, reina Mary I de Escocia. El filme nos

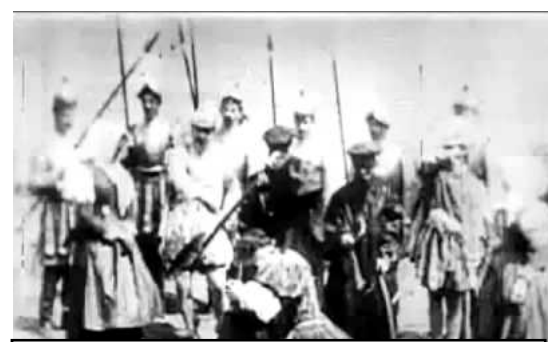

Figura 1. Fotograma de Mary Queen of Scots. (Alfred Clarke, 1895) presenta su decapitación, para la cual, se sustituyó a la actriz por un maniquí. Para realizar el efecto correctamente, se paró la cámara antes de que el verdugo bajase el hacha. En su lugar y misma posición se colocó un maniquí, haciéndose efectivo el truco. De igual manera, este efecto se utiliza en ciertas películas como La manoir du diable (Méliès, 1896) o The Enchanted Drawing (Stuart Blackton, 1900), sin tenerse en cuenta como un recurso que por sí solo nos cuenta una historia, sino que se trata de una herramienta a través de la que llevar a cabo estos trucos. No estamos ante películas de animación pero "Este tipo de realización cinematográfica fue el precursor de varias ramas diferentes en el árbol del stop motion, incluyendo los efectos especiales modernos, el stop motion de títeres o modelos, y la pixilación y sus diversas formas" (Tom Gasek, 2017:4).

El cine mágico es similar al del trucaje, ya que utiliza el mismo recurso de la sustitución por stop motion. La diferencia radica en que el cine de trucaje utiliza este recurso en momentos puntuales y el mágico se vale de él para recrear espectáculos que previamente se realizaban en los teatros. Como cine mágico, que se extiende aproximadamente hasta el 1.900, englobamos el título Escamotage $d$ 'une dame chez Robert-Houdin (1896) realizada por Georges Méliès. En el filme Escamotage d 'une dame chez Robert-Houdin, Méliès pone en práctica un truco que solía escenificar en su teatro. Una mujer se sienta en una silla, se le pasa un velo por delante y desaparece. En el teatro, la actriz desaparecía por una trampilla. En la película ocurre casi lo mismo con la variante de que la actriz desaparece para ser sustituida por un esqueleto. Podemos observar el truco de sustitución casi a mitad de cinta, cuando el propio Georges Méliès cubre a la actriz con un paño, dejando al descubierto parte del vestido de la misma. Tras la tela (fig.2) se puede apreciar parte del vestido de la actriz que inmediatamente después, en el fotograma siguiente, desaparece (fig.3). Por lo tanto, se induce que la cámara se paró en dicho fotograma y se reinició en el siguiente. En este momento la actriz se levanta de la silla y se va, dejando a Méliès en la misma pose sujetando el velo para mantener la continuidad. El siguiente truco de sustitución lo realiza más adelante, cuando la silla se queda vacía en el plano. Detiene la cámara cuando él está levantando las manos y de ahí coloca un esqueleto en la silla (figuras 4 y 5 ) para que el espectador lo reciba como una aparición repentina.
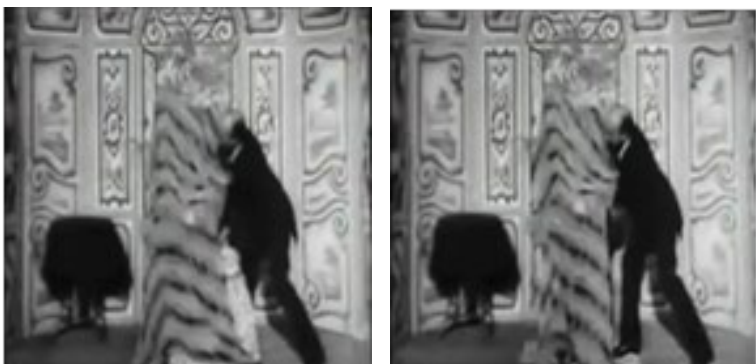

Figura 2 y Figura 3. Fotograma de la película Escamotage d'une dame chez Robert-Houdin (Méliès, 1896)
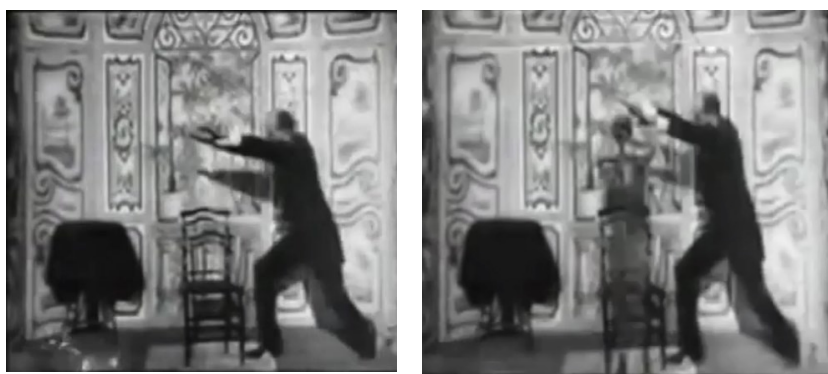

Figura 4 y Figura 5. Fotogramas consecutivos de la película Escamotage d'une dame chez Robert-Houdin (1896

Por último, la cámara debe detenerse para hacer reaparecer a la actriz en el lugar del esqueleto. Esta vez es más complicado mantener el paño en la misma pose, por lo tanto, la cámara debe detenerse justo antes de tapar por completo la silla (fig.6). Aquí el truco de sustitución es más notorio, debido a que existe un cambio de luz. Probablemente en el momento en el que se quitó el esqueleto, Méliès aprovechó la parada para que la actriz volviese a sentarse en la silla, ya que no se aprecian más cortes en la película.

Estos fotogramas que acabamos de analizar corresponden al momento en el que el cineasta paró su cámara y la reinició, probablemente con ayuda, ya que él es el actor principal y para mantener la continuidad no puede salir de plano. Estamos, por lo tanto, ante una película que usa la técnica del reemplazo por stop motion.

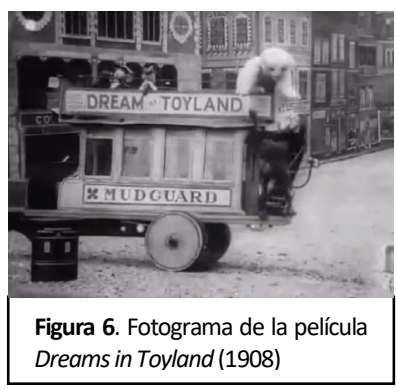


Si seguimos analizando películas de temática mágica que utilizan el paso de manivela, nos encontramos con la película de Georges Méliès, The conjurour (Méliès, 1899) en la que se vale del truco de sustitución para hacer y desaparecer a una bailarina y un mago. Ambos se reemplazan mutuamente para generar un espectáculo de magia a través del paso de manivela o "stop motion substitution" como lo denominó Charles Musser. Sin embargo, estas películas no son consideradas animaciones stop motion debido a la falta de rodaje fotograma a fotograma en su totalidad.

Después de este período de cine mágico categorizado como proto-stop motion, la técnica evoluciona. Ciertos cineastas como Stuart Blackton comienzan a experimentar con ella hasta crear secuencias animadas fotograma a fotograma como en The Haunted Hotel (Blackton, 1907). No estamos ante una película enteramente de animación pero sí nos encontramos ante un segmento en el que vemos cómo los elementos en pantalla levitan gracias a la técnica de proyección fotograma a fotograma. Tras la experimentación con objetos y gracias al desarrollo de la industria del juguete, comienzan a incluirse todo tipo de muñecos a narraciones de corte fantástico, como por ejemplo Dreams in Toyland (Melborune Cooper, 1908) en la que osos de peluche y coches de juguete cobran vida. La técnica del stop motion evoluciona hasta incluir el uso de marionetas articuladas concebidas específicamente para ser animadas como apoyo a los efectos especiales en el cine. Paralelamente, aparecen películas realizadas completamente con esta técnica en las que el stop motion ya es un medio independiente del cine, en el que la narración y los personajes cobran gran importancia. Este período de descubrimiento y experimentación culmina con El Mundo Perdido (Harry O. Hoyt, 1925) que ayuda al establecimiento de la animación stop motion como arte (Harryhausen y Tony Dalton, 2008:38).

\section{CONCLUSIONES}

El stop motion más primitivo es utilizado en un inicio como truco meramente recursivo y sin pretensiones de ser animación. Tras el análisis de algunos de los primeros filmes realizados, observamos que contienen estos recursos técnicos. Determinamos entonces que las apariciones más primitivas del stop motion se encuentran en dos grupos de películas que clasificamos como cine mágico y de trucaje. El trucaje en el cine, la sustitución o el paso de manivela permite a magos y cineastas crear trucos de mayor complejidad, de una manera más sencilla, parando la cámara y sustituyendo actores u objetos. "Si alguna técnica predecesora de la animación debe ser identificada, podría ser la técnica de sustitución por la parada de acción" (Crafton, 1982:9). Este recurso técnico permite llevar a cabo historias fantásticas y evolucionará hasta convertirse en una herramienta con base creativa para muchos autores, que la manejan y mejoran hasta cristalizarse como animación stop motion.

Por lo tanto, proponemos el término proto-stop motion como la categoría desde la que situarnos para comprender, a través de una nueva mirada, la taxonomía del stop motion. Dentro de esta categoría, incluimos las clasificaciones en cine mágico y cine de trucaje, que se proponen como contenedoras de las muestras más primitivas, para el asentamiento de una nueva técnica animada, que en un futuro será independiente del cine.

\section{FUENTES REFERENCIALES}

Crafton, D. (1.982). Before Mickey (1a ed.). Massachusetts: The MIT Press.

Cuéllar, C. (1.999) El protocine y su entorno: Un estado de la cuestión. Archivos de la filmoteca: Revista de estudios históricos sobre la imagen, 33, 177-180.

Furniss, M. (2017). Animation the global history (1a ed.). Londres: Thames \& Hudson.

Gassek, T. (2017). Frame-by-Frame Stop motion. The guide to Non-puppet Photographic Animation Techniques (2 ${ }^{\text {nd }}$ ed.). Estados Unidos: CRC Press.

Gubern, R. (2014). Historia del cine (1 1 ed.). Barcelona: Anagrama.

Harryhausen, Ray., Dalton, Tony. (2008). A century of stop motion animation: From Méliès to Aardman (1ạ ed.). Estados Unidos: Watson-Guptill.

Martínez-Barragán, C. (2011). Metodología cualitativa aplicada a las Bellas Artes. Revista Electrónica de Investigación, Docencia y Creatividad, DOCREA 1, pp. 46-62.

Nelmes, J. (2003). An introduction to film studies (3 ${ }^{\text {rd }}$ ed.). London: Routledge. 